\title{
Estereotipos de la representación del cuerpo en la televisión. Aspectos de la crítica de la cultura de masas de Th. W. Adorno
}

\author{
Stereotypes of the body representation on television. \\ Aspects of the critique of mass culture Theodor Adorno
}

MATEU CABOT*

\begin{abstract}
Resumen: En este texto estudiamos el mecanismo de la estereotipación en la representación del cuerpo tal como se muestra en la televisión. Partimos de anteriores trabajos en los que analizamos los trabajos de Adorno sobre le recepción masiva de la televisión en los años cuarenta y la consiguiente homogeneización de los estándares del gusto. Concluimos extrayendo las posibilidades críticas de los conceptos analíticos utilizados por Adorno y la pertinencia contemporánea del método de investigación aplicado.

Palabras clave: representación del cuerpo, medios audiovisuales, estereotipos, Adorno.
\end{abstract}

\begin{abstract}
In this paper we study the mechanism of stereotyping in the representation of the body as shown on TV. We start from previous jobs that analyze the work of Adorno on her massive TV reception in the forties and subsequent homogenization of standards of taste. We conclude extracting the critical possibilities of analytical concepts used by Adorno and contemporary relevance of the research method applied.
\end{abstract}

Keywords: body representation, media, stereotyping, Adorno.

\section{Introducción: tema y objetivos del texto}

En este texto nos ocupamos de la representación ${ }^{1}$ del cuerpo en la televisión. Nuestro objetivo es analizar el efecto semi-formativo que ejerce la televisión en lo que se refiere a los modelos de "cuerpo" socialmente dominantes. Partimos de anteriores investigaciones en

Fecha de recepción: 09/06/2016. Fecha de aceptación: 06/09/2016.

* Universitat de les Illes Balears, Profesor Titular de Filosofía, mcabot@uib.es Líneas de investigación: Theodor W. Adorno; Teoría Crítica; Estética negativa. Publicaciones recientes: «El 'descubrimiento moderno de la oralidad' y los medios audiovisuales» (2015); «Abschied von der Schule? Von den alphabetisierenden Schule zur diffusen Audio-Visualität» (2015).

1 Utilizamos el término "representación" en el sentido que tiene en la terminología kantiana el de Vorstellung. Vid. Eisler, R., Kant-Lexikon. Nachschlagewerk zu Kants sämtlichen Schriften, Briefen und handschriftlichen Nachlaß. Hildesheim: Georg Olms Verlagsbuchhandlung, 1964. En especial: "Durch den Verstand (s. d.) werden die Vorstellungen zur Einheit verknüpft. Die Gegenstände der Erfahrung, die Erscheinungen, sind (als solche) nicht außerhalb des gesetzmäßig bestimmten Zusammenhanges möglicher Vorstellungen”. 
las que concluimos que el carácter semi-formativo de la televisión residía en la estructura y funcionamiento del sistema televisivo, y no en supuestos defectos del espectador ${ }^{2}$. Pretendemos focalizar sobre la representación del cuerpo el planteamiento y las conclusiones de la anterior investigación, con la hipótesis de que dicha perspectiva de estudio del cuerpo, a partir de su reflejo como imagen en la televisión, tiene cabida en el campo de la antropología filosófica. Al contrario de la tendencia dominante en dicha disciplina, fundamentalmente idealista, la perspectiva de estudiar el hombre (un sentido muy laxo de antropología filosófica, somos conscientes de ello) teniendo como guía la estructura que hace posible el reflejo del hombre y del mundo, como estructura económica y social determinada, es fundamentalmente materialista.

\section{La antropología filosófica y la corporalidad}

En el campo de la antropología filosófica la cuestión de la corporalidad está presente como problema desde mucho antes de que Max Scheler estableciera su definitivo estatus académico con un texto en el que afirma: "En ninguna época de la historia ha resultado el hombre tan problemático para sí mismo como en la actualidad"3. En la sociedad de masas se hace evidente la endeblez del concepto "hombre" hasta ese momento no tematizado de forma suficientemente radical. El primer problema del concepto es fundarse en un dualismo de cuerpo y espíritu tan radical como insostenible a la luz del conocimiento presente: "Por ende, no cabe seguir hablando seriamente de un nexo entre la sustancia psíquica y la sustancia corporal, tan externo como el supuesto por Descartes. Es una y la misma vida la que posee, en su 'ser íntimo', forma psíquica y, y en su ser para los demás, forma corporal"4.

La explicación cartesiana del hombre como un compuesto de res cogitans y res extensa, insostenible según Scheler, es consecuencia del principio general que en la edad moderna lo regula y gobierna todo, a saber, "el pensamiento que parte de sí mismo". Esta es la interpretación de Hegel, que al hacer de la Modernidad la edad de la razón y, por tanto, de la crítica $^{5}$, erigirá el marco de nuestra época: “con Descartes entramos en una filosofía propia e independiente, que sabe que procede sustantivamente de la razón y que la conciencia de

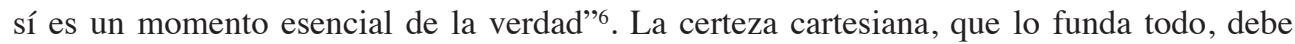
admitir, en la última de las Meditaciones metafísicas, que "lo que la naturaleza me enseña más expresamente es que tengo un cuerpo, que se halla indispuesto cuando siento dolor, y que necesita comer o beber cuando siento hambre o sed, etc." Por "mi naturaleza", dirá, "no entiendo otra cosa que la ordenada trabazón que en mí guardan todas las cosas que Dios me ha otorgado7. "Ordenada trabazón" es la relación entre las partes, res cogitans y extensa, que constituyen el todo, el hombre, en un razonamiento que debe circunscribirse, como señala en

2 Cabot, M., "Carácter semiformativo de los medios audiovisuales. Las investigaciones empíricas de Theodor W. Adorno sobre la televisión", Pensamiento [En prensa].

3 Scheler, M., El puesto del hombre en el cosmos, trad. de J. Gaos. Buenos Aires: Losada, 1982, p. 24. La primera publicación de la conferencia es inmediatamente posterior a su repentina muerte en 1928.

4 Scheler, M., op. cit., p. 91.

5 Duque, F., Historia de la filosofía moderna. La era de la crítica. Madrid: Akal, 1998, p. 15ss.

6 Hegel, G.W.F., Lecciones sobre la historia de la filosofía, op. cit., p. 252.

7 Descartes, R., Meditaciones metafísicas con objeciones y respuestas, trad. de V. Peña. Madrid: Alfaguara, 1977, p. 68 . 
el prólogo, al ámbito de la "certeza". El cuerpo aparece como naturaleza que siente dolor y necesita alimentarse y que, siendo distinta de la substancia pensante, su comprensión no es en absoluto inmediata. Es ilustrativo que Descartes tuviera que llegar a postular la "glándula pineal" como lugar en que se traban ambas naturalezas ${ }^{8}$.

Descartes convierte la interacción entre el espíritu y el cuerpo en problemática y Hegel levanta acta en la tercera parte de su Enciclopedia de las Ciencias Filosóficas, la dedicada al "espíritu". Argumenta la imposibilidad de explicar dicha interacción en el sentido común, de modo que "según la respuesta corriente puede decirse que esta unión es un misterio inconcebible”. Las explicaciones dadas por Descartes, Malebranche, Spinoza y Leibniz

han puesto todos ellos a Dios como tal relación y precisamente en el sentido de que la finitud del alma y de la materia sólo son determinaciones recíprocamente ideales y no tienen ninguna verdad; de este modo Dios, según estos filósofos, no es meramente otra palabra para aquella incomprensibilidad, como ocurre frecuentemente, sino que él más bien se capta como la única verdadera identidad de cuerpo y alma9 ${ }^{9}$

Pensar dicha identidad deberá plantearse de otra forma, la que proseguirá Hegel será plantear la relación que ha de conducir a la unidad, no como entre dos substancias abstractas, formalmente puras, sino como una unidad haciéndose progresivamente gracias a la tensión dialéctica entre sus partes. Como resultado, el desarrollo posterior de la antropología ha incidido en este punto y, según un reconocido manual de antropología filosófica, "la corporalidad ha adquirido particular fuerza, abandonando el dualismo de los siglos pasados", de modo que ha puesto en primer plano la corporalidad en el hombre que, en su existencia concreta, "como ser-en-el-mundo y como espíritu en el mundo. De este modo la corporalidad ha pasado a ser considerada como rasgo esencial del hombre" 10.

Creemos pertinente, para analizar su existencia concreta como ser-en-el-mundo, el conocimiento de los medios con los cuales ese ser está-en-el-mundo, esto es, cómo se representa la forma de su existencia concreta, y como moldea su representación del cuerpo en el mundo según las representaciones dominantes en el mundo en el que en cada caso concreta su existencia. Además de las condiciones técnicas y sociales que determinan la representación en las sociedades contemporáneas ${ }^{11}$, cuyo análisis se inició a principios del siglo XX y que retomaremos seguidamente, queremos señalar otra dimensión que ofrece argumentos para el planteamiento de este trabajo, a saber: el mecanismo por el cual se materializa la determinación social; más en concreto: que mecanismos fisiológicos y materiales, modificables por el entorno social, intervienen en la determinación de la imaginación, el sentido del tiempo o el deseo de los individuos particulares.

8 Descartes, R., Las pasiones del alma, trad. de T. Onaindia. Madrid: Edaf, 2005, p. 78-79.

9 Hegel, G.W.F., Enciclopedia de las ciencias filosóficas en compendio. trad. de R. Valls. Madrid: Alianza Editorial, 2005, p. 442.

10 Amengual, G., Antropología filosófica, Madrid: BAC, 2007, p. 57.

11 Marx, K., "Contribución a la crítica de la economía política", 1858, Prefacio. 


\section{Cuerpo y placer escópico}

En "El estadio del espejo como formador de la función del yo tal como se nos revela en la experiencia psicoanalítica", un texto de 1949 seminal en muchos sentidos, Jacques Lacan aseguró que la experiencia de la llamada "identidad personal" que se deriva de la práctica psicoanalítica "se opone a toda filosofía derivada directamente del cogito"12. La propuesta de Lacan, en seminarios de análisis de su práctica como terapeuta psicoanalista, remite así al momento fundacional de la conciencia moderna: la autoposición del yo, pues el "ego" cartesiano no tiene otro fundamento sobre el que apoyarse como fuente del conocimiento, estableciéndose así además la certeza de la evidencia inmediata como criterio de verdad. De la mano de la lectura que Alexander Kojeve realizó de la Fenomenología del espíritu de Hegel ${ }^{13}$, Lacan entenderá ese "yo (je)" como resultado de un proceso dialéctico de identificación respecto a otro yo (real o imaginario). Otro yo que se nos hace presente con su cuerpo ante nuestra mirada. En el seminario 11, dictado en la primera mitad de 1964, Lacan afirma: "En nuestra relación con las cosas tal como es constituida por la vía de la visión y ordenada en las figuras de la representación, algo se transmite de piso en piso para estar siempre en ella en algún grado elidido -eso es lo que se llama la mirada"14.

La diferencia entre la visión y la mirada es la disolución de una supuesta inmediatez del mundo visual, la pretendida "naturalidad" del mirar y ver, esto es, la persistencia del pensamiento pre-moderno de la naturalidad en el ser humano; precisamente el tipo de pensamiento impugnado por Freud. Precisamente el objeto del análisis de Lacan es la diferencia entre el ojo natural, construcción ya él mismo, en cuanto lo natural está plenamente socializado, y la mirada, esto es, el conjunto de modelos de representaciones que se actualizan en cada mirada singular. Dirá Lacan: "El ojo y la mirada, tal es para nosotros la esquizia en la que se manifiesta la pulsión al nivel del campo escópico"15. Con ello Lacan sitúa en el mapa el lugar que ocupa la pulsión escópica en la construcción de los modelos de representación, esto es: cómo se articula el deseo en la construcción de imágenes, casi podría decirse: de qué manera el deseo, aquello que colmara de placer mi imaginario particular, crea los modelos o estereotipos de imágenes que son, precisamente, repetición de mi imaginario, ya que no es "mi" imaginario sino en cuanto lo he absorbido de las fuentes de la industria cultural.

12 Lacan, J., "El estadio del espejo como formador de la función del yo [je] tal como se nos revela en la experiencia psicoanalítica", en: Escritos I, trad. T. Segovia. Madrid: Biblioteca Nueva, 2013, p. 99.

13 Kojeve, A., Introducción a la lectura de Hegel, trad. de A. Alonso. Madrid: Trotta, 2013. Sobre este paso filosófico cf. Stavrakakis, Y., Lacan y lo político, trad. de L. Barbieri y M. Valente. Buenos Aires: Prometeo Libros, 2007, cap. 1: "El sujeto lacaniano. La imposibilidad de la identidad y la centralidad de la identificación”, pp. 31-68. Cf. Roudinesco, E., La batalla de los cien años: historia del psicoanálisis en Francia, trad. de I. Gárate. Madrid: Fundamentos, 2000.

14 Lacan, J., "La esquicia del ojo y de la mirada", op. it., clase 11.

15 Lacan, J., "La esquicia del ojo y de la mirada", Seminario 11: Cuatro conceptos fundamentales del psicoanálisis (1964), Clase 4. Le séminaire. Livre XI, Les Quatre concepts fondamentaux de la psychanalyse: [texte établi par Jacques-Alain Miller]. Paris, Éd. du Seuil, 1990. Citamos según la versión: Jacques Lacan, "Séminaire Les quatre concepts fondamentaux de la psychanalyse. Les fondements de la psychanalyse", Essaim, 2006,2 (n. ${ }^{\circ}$ 17), pp. 65-82. DOI 10.3917/ess.017.0065 
Con ello se trata de dar un paso más en el primer análisis realizado por los psicólogos de la Gestalt, que se limitaron a las estructuras a nivel fisiológico y de procesos conscientes ${ }^{16}$. Contemporáneos al nacimiento y auge del cine, la psicología de la Gestalt y el psicoanálisis freudiano aportarán a la comprensión de la percepción, y más concretamente, de la percepción estética, una explicación del carácter socialmente necesario del modo de ver y del carácter socialmente condicionado de la organización libidinal que sustenta el placer escópico. Juntas ofrecerán una explicación tanto del enorme éxito y la penetración vertiginosa del cine en el mundo de la diversión de masas, como de su poder para modificar la conducta de los sujetos.

Sobre lo primero: desde 1895 la imagen cinematográfica cautivó a todos aquellos que se convertían en espectadores. Medio siglo después la posesión de un aparato reproductor de imágenes cinematográficas, un televisor, se convirtió en la puerta de entrada en la clase media, en el sentido universal de dicho término: aseguramiento de la supervivencia al precio de la renuncia -consciente- a la auto-determinación, en sentido kantiano, la felicidad.

Sobre esto último ya había llamado la atención Freud en 1915, en la primera de sus Conferencias de introducción al psicoanálisis, cuando considera las dificultades que se presentan al psicoanálisis. En el tratamiento psicoanalítico, dice, "el médico escucha, procura dirigir las ilaciones de pensamiento del paciente, exhorta, empuja su atención en ciertas direcciones, le da esclarecimientos y observa las reacciones de comprensión o rechazo que de ese modo provoca en el enfermo", lo cual provoca que "los parientes incultos de nuestros enfermos" no dejen de manifestar sus dudas de que "meras palabras puedan lograr algo con la enfermedad". Freud define a estos "parientes incultos" como "a quienes solamente les impresiona lo que se ve y se palpa, de preferencia las acciones como se ven en el cinematógrafo ${ }^{17}$ ". Esto es: "Lo que ven en el cinematógrafo" desplaza la autoridad científica y social del médico mediante la reducción de su autoridad científica a "mera opinión" o negándola en nombre del "sano" sentido común"18.

\section{Construcción de imágenes en movimiento}

Walter Benjamin abrió el camino al atisbar el significado radical de la cinematografía: analizó las modificaciones que provocaba el nuevo medio técnico sobre la entera estructura del arte, tal como se había entendido en los últimos siglos, e incluso sobre la estructura perceptiva del ser humano ${ }^{19}$ ). Con ello abría un nuevo nivel en las consideraciones antropológicas del momento, dependientes aún demasiado estrictamente de la antropología de Kant.

16 Max Wertheimer (1924), "Über Gestalttheorie”, Vortrag vor der Kant-Gesellschaft, Berlin, am 17. Dezember 1924. Abgedruckt in Philosophische Zeitschrift für Forschung und Aussprache 1, 39-60 (1925) und als Sonderdruck: Erlangen: Verlag der philosophischen Akademie (1925). Reprint in: Gestalt Theory, Vol. 7, № 2, 99-120, Opladen: Westdeutscher Verlag, 1985.

17 Freud, S., "Conferencias de introducción al psicoanálisis", Obras Completas, vol. 15, Buenos Aires: Amorrortu, 1991, p. 14.

18 Hegel criticará la autoafirmación sin reconocimiento de la diferencia, tal es la definición de "opinión", con la fórmula "Meine Meinung ist meine", aprovechando la proximidad sonora de "opinión" (Meinung) y "mio" (mein). Hegel, G.W.F., Phänomenologie des Geistes, in: Werke. Band 3, Frankfurt: Suhrkamp, 1979, p. 84.

19 Benjamin, W., "La obra de arte en la época de su reproductibilidad técnica", en: Ibíd., Obras, vol. I-2, Madrid: Ábada, 2008, p. 56. 
En este paso se ayudaba tanto de la psicología de la percepción como de la psicología de lo profundo, en ambos casos en las formas científicamente más avanzadas del momento: la teoría de la Gestalt y la metapsicología de Freud. En un trabajo anterior analizamos la crítica que Benjamin realiza de la imagen cinematográfica fijándose en la modificación de la experiencia de los individuos a que obliga la aparición de este tipo de imágenes. La idea clave en todo ello la expone él mismo al final de la tesis XI: "Así, para el hombre actual, la representación cinematográfica de la realidad es incomparablemente más significativa porque, precisamente, en razón de esa tan intensa penetración con el aparato, garantiza el aspecto de lo real libre de aparatos que él tiene el derecho de exigir de la obra de arte"20. Esta tesis sirve para explicar el plus de gratificación que tiene la imagen cinematográfica en cuanto consigue recrear el "Ojo de Dios": ver la realidad, toda la realidad, desde el punto de vista de Dios, esto es: sin la visión de aparatos que sostengan la ficción. El teatro creaba una realidad ficcional que no podía esconder la tramoya y toda la maquinaría teatral, pero en el cine el ojo del espectador coincide con el ojo de la cámara, el objetivo, ante el cual debe mostrarse toda la realidad si quiere ser registrada. Esto permite conectar "aquello que veo en la pantalla" con "aquello que existe para mi" y, de esta manera, transferir a la ficción cinematográfica el papel de super-yo que en el mundo no ficcional se encuentra cada vez más debilitado ${ }^{21}$. La imagen cinematográfica del cuerpo no es solo representación del cuerpo o del mundo, sino que, como ya señaló Benjamin, es recreadora del mundo en torno: "El cine no se define en absoluto tan solo por el modo por el que el hombre se sitúa ante el tomavistas, sino por el modo en el cual, con su ayuda, éste se representa el mundo entorno"22.

La industria cultural posee un alto poder de modificación del psiquismo de los individuos posibilitado por la propia estructura de los medios técnicos que se utilizan en dicha industria. La producción y reproducción industrial de imágenes y sonidos despoja a estas imágenes y sonidos de todo carácter aurático, como lo denominó Benjamin. Esto es, imágenes y sonidos que precisan de un contexto para que adquieran significado pero que pierden todo contexto una vez que son producidas y reproducidas mecánicamente. En la imagen cinematográfica el contexto de sentido podrá surgir de las propias imágenes, superando así a las fotografías que se incluían en los periódicos y que precisaban de un pie de página para que adquirieran algún sentido. Como escribirá Benjamin: "Las directrices que al que observa las imágenes de una revista ilustrada le da el rótulo no tardarán en hacerse aún más precisas y más imperativas en el cine, donde la concreta comprensión de cada imagen individual aparece prescrita por la secuencia de las precedentes"23. Lo dicho por Benjamin es aceptado por Adorno: "La nueva técnica se diferencia del cine en que, al igual que la radio, lleva el producto a casa de los consumidores ${ }^{24}$ ". El potencial de la televisión como creador de falsa conciencia fue la línea de investigación que Adorno desarrolló en la década de 194025. Para Adorno, al potencial

20 Benjamin, op. cit., p. 74.

21 Cabot, M., «Sobre los medios técnicos y la renovación de tradiciones. Walter Benjamin y el concepto de "experiencia", pensado desde la estética», en: Amengual, G., Cabot, M., Vermal, J.L., Ruptura de la tradición. Ensayos sobre Benjamin y Heidegger, Madrid: Trotta, 2007, pp. 61-82.

22 Benjamin, W., "La obra de arte ...", op. cit., p. 75.

23 Benjamin, op. cit., p. 63.

24 Adorno, T.W., "Prólogo a la televisión", OC, 10.2, p. 446.

25 Cabot, M., "Carácter semiformativo de los medios audiovisuales. Las investigaciones empíricas de Theodor W. Adorno sobre la televisión", Pensamiento.[En edición] 
del cine en cuanto conformador de las conciencias, que ya había analizado Benjamin, se incrementaba notablemente cuando la maquinaria de recepción de la ideología dominante se trasladaba al interior de los hogares. Primero con la radio y más tarde con la televisión, el modelo de existencia prescrito para los individuos incluye la necesaria presencia en el corazón del hogar típico del american way of life, de los aparatos receptores: esta es una evolución que significa una mayor y más amplia penetración en el psiquismo de los individuos oyentes y espectadores.

\section{Dominación sigilosa y otras formas de "servidumbre voluntaria"}

El hogar de la familia nuclear del capitalismo de consumo de la posguerra norteamericana es el lugar donde se refugia el individuo moderno: el espacio público ha sido colonizado por el mercado, transformándose por tanto en un espacio de mercancías. La promesa del capitalismo es aliviar los dolores del sacrificio mediante el consumo conspicuo, transacción que se convertirá, no sin una continua negociación, en el mecanismo fundamental para la servidumbre voluntaria que abrazarán los individuos en el capitalismo desarrollado. Como escribió Freud en 1930: "Puesto que la cultura impone tantos sacrificios no sólo a la sexualidad, sino a la inclinación agresiva del ser humano, comprendemos mejor que los hombres difícilmente se sientan dichosos dentro de ella"26.

Además de las funciones de abrigo y vida de la familia como célula de la sociedad, el hogar deberá ser refugio y compensación de aquellos sacrificios que impone el orden social. La inviolabilidad del hogar, sweet home, permite a sus habitantes una relajación del estado de alerta permanente de la vida moderna, también de los mecanismos psíquicos de auto-control o etiqueta social. En el "hogar" de "clase media", aparentemente reflejado en la televisión y el cine, ha de tener lugar la reparación diaria de la fuerza de trabajo, después del desgaste psíquico extra que supone un modo de vida menos exigente físicamente. Freud analizó en El malestar en la cultura la dinámica psíquica. Esa dinámica sucede en el salón de TV del hogar de clase media: la butaca o sofá proporciona la reparación física, destensando las defensas ante las agresiones y esfuerzos del exterior, esa desconexión se consigue con una conexión psíquica a la red de televisiones del mundo. Red que transmite un determinado, concreto y políticamente interesado modelo de: cuerpo, género, mundo, explotación social, pobreza, capitalismo, etc. En definitiva, en el hogar se piensa cabeza abajo el Discurso sobre la servidumbre voluntaria ${ }^{27}$.

El ensamblaje de todos los sectores del capitalismo se hace visible en el modo de experiencia en la que la televisión ocupa un lugar relevante: una ampliación sin precedentes del ciclo de producción, circulación y consumo de mercancías, con el consiguiente aumento de los sacrificios de los individuos, y un rebajamiento de las tensiones sociales mediante la inoculación de mayor docilidad ${ }^{28}$.

26 Freud, S., "El malestar en la cultura", in: Obras Completas, vol. 21, Buenos Aires: Amorrortu, 1991, p. 111.

27 Cf. La Boétie, E., Discurso de la servidumbre voluntaria o el contra uno, trad. de P. Lamba. Madrid: Trotta, 2008.

28 Zamora, J.A., "El enigma de la docilidad", en: Cabot, M. (ed.), El pensamiento de Th. W. Adorno: balance y perspectivas. Palma de Mallorca: Edicions UIB, 2007, pp. 27-42. 
Dentro de las directrices interpretativas, aquellas que afectan al cuerpo humano, además de cumplir las funciones dichas de economía productiva y recepción dirigida, tienen un extra en cuanto que el objeto de representación es, a la vez, el sujeto de la interpretación. Los productos de la industria cultural presuponen, sea o no el objeto inmediato de representación, una representación institucionalizada del cuerpo, tanto en su figura como en sus propiedades más importantes, y esta representación se convierte en modelo socialmente aprobado a imitar o en enemigo que unifica y condensa los malestares provocados por el trabajo y la represión. Si el niño se constituye ante el espejo con (su) reflejo, esto es lo que tiene que descubrir para crecer, ahora el reflejo está animado por detrás, es una pantalla, ya no hay posibilidad de quitar los paréntesis a (su) reflejo y entonces es reflejo, y nada más. La conjunción de factores condujo a que la televisión se convirtiera en agente socializador de una manera más amplia que la propia familia.

Pero aunque el tema parece ser de consumo de mercancías de la industria cultural, este es dependiente del de la producción de dichas mercancías. Al tratar de la producción, la distribución y el consumo, en contra de los economistas burgueses que afirman interesadamente la prioridad de uno u otro proceso económico, Marx demostrará la necesaria interrelación entre producción, distribución y consumo, además de poner de relieve el condicionamiento social del consumo por el hecho de que solo puede consumirse lo que puede ser producido. En 1969 Adorno escribirá: "Hay razones para suponer que la producción regula el consumo tanto en el proceso material de vida como en el espiritual, en especial donde se ha aproximado tanto a la producción material como en el caso de la industria cultural ${ }^{29}$ ".

My Life and Work de Henry Ford es la muestra del cambio de reglas de producción industrial $^{30}$. Su modo de organización científica de la producción fue aplicado en todas las ramas de producción por efecto de la competencia y el aumento de productividad que significa el I+D. La producción en cadena precisa, para ser rentable, la reducción de la complejidad a tareas simples y repetidas, y la reducción de la multiplicidad a una variabilidad facilitada por la modularidad. La industria cultural de principios del siglo xx aplicó estrictamente estos principios. En el caso de la industria del cine las necesidades de una producción ampliada de mercancías y la relativa diversidad del gusto de los consumidores fue resuelta con la formación de una serie limitada de tipos, fácilmente identificables y con posibilidades de una relación modular entre ellos. La creación de estereotipos fue identificada por Adorno ${ }^{31}$ como una de las herramientas para conseguir todos los objetivos al mismo tiempo, tanto los económicos de rentabilidad, como los políticos de aumento de la docilidad social. La creación de estereotipos en la cultura de masas tiene la misma función económica que la serialización en la producción material: reducir costes de producción por unidad producida; y la misma función socializadora que la familia o comunidad: mantener el grupo con vida frente a enemigos externos e internos.

29 Adorno, T.W., "Freizeit", GS, 10.2, p. 653.

30 Ford, H., My Life and Work, New York: Doubleday, Page \& Co., 1923.

31 Adorno, T.W., "Prólogo a la televisión", OC, 10.2, p. 474. 


\section{Modelos de ver y de ser-en-el-mundo}

La estereotipificación o serialización necesaria a la producción masiva en el capitalismo de consumo, se concreta en representaciones del cuerpo que sirven al doble objetivo económico y social. La cohesión social y la sumisión de los individuos, detectadas desde los Estudios sobre la personalidad autoritaria de $1950^{32}$, conlleva la construcción de personajes, situaciones, esquemas comprensivos de la realidad que se materializaran en los medios audiovisuales de masas mediante un actor que presta su cuerpo pero que no ha de interpretar nada más que su personaje. Con ello Benjamin esclarece las diferencias entre el actor de teatro y el de cine. El cuerpo puede convertirse en un objeto masivo de representación pública precisamente porque se ha desligado del cuerpo que le ha posibilitado ser visto, ser sensible. Esto es: se ha vuelto abstracto. Y al volverse abstracto ya no hay límites para la fantasía de recursos de manipulación que puedan poner en juego los estudios de televisión, cine y música, con sus departamentos comerciales y de prospección de audiencias.

La serialización en todos sus aspectos (de caracteres, de cuerpos, de escenas, de miradas, etc.) sólo explica la adopción de un mecanismo viable para la producción, pero no explica el contenido de los modelos serializados, explicación para lo cual es preciso acceder al lugar al que accede la industria cultural: la conciencia de esos individuos espectadores. En esa conciencia es donde deberá producirse la negociación en términos de sacrificios y recompensas para que la economía libidinal sigue aportando sus energías para la reproducción del ciclo económico.

\section{Conclusiones y líneas abiertas}

A partir de los análisis anteriores es posible indicar conclusiones en forma de líneas de investigación abiertas. Es preciso retornar a los análisis de contenidos que permitan poner en práctica los conceptos analíticos utilizados por Adorno. Dos líneas son especialmente interesantes a nuestro entender:

La primera incide sobre las "promesas incumplidas": De ahí que: la pretendida inmediatez de la imagen cinematográfica, la promesa de inmediatez (de disfrute inmediato), es la promesa de la industria cultural que ella sabe que no puede cumplir. La inmediatez aparente de la representación del cuerpo en imágenes cinematográficas es posible en cuando esa representación es abstracta y debe ser previamente aprendida a interpretar según las indicaciones aportadas por imágenes anteriores. Los análisis de los programas radiofónicos Martin Luther Thomas realizados por Adorno en 1943 muestran la técnica psicológica de este agitador filofascista, utilización que se convierte en todo un catálogo de "estratagemas" de convicción ajustadas al medio radiofónico en el que se utilizarán ${ }^{33}$. La televisión y el cine, que al ser audiovisuales deben representar necesariamente el cuerpo, podrá disponer de los medios para manejar representaciones clave del deseo y de la agresividad humana. La representación del cuerpo de la mujer en la cultura occidental, para el deseo, y de la figura

32 Adorno, T.W., "Estudios sobre la personalidad autoritaria”, OC, 9.1, pp. 147-525.

33 Adorno, T.W., "La técnica psicológica de las alocuciones radiofónicas de Martin Luther Thomas", in: OC, 9.1, pp. 9-141. 
del "judío" (en la Alemania nacionalsocialista) o del "terrorista" (en nuestro presente), para el miedo, son el resultado final de la construcción social de dichas realidades, abstractas y audiovisuales, pero no por ello menos efectivas, sino mucho más pues con ellas no cabe encontrárselas fuera de la ficción de la industria cultural.

La segunda incide sobre las contradicciones de la noción de "realidad" (y, por consiguiente, "ficción") que debe acompañar toda representación audiovisual que pretenda conseguir sus objetivos. En la representación del cuerpo la contradicción emerge entre el carácter abstracto de las representaciones necesariamente estereotipadas y abstractas con la pretensión de inmediatez y corporalidad que pretende transmitir, pues la representación audiovisual del cuerpo es una representación del cuerpo comercial, pero no la singularidad del cuerpo siempre propio y mío, de un individuo perteneciente a una clase determinada en una sociedad determinada. Frente a este la representación audiovisual del dolor, de la experiencia de dolor y sufrimiento, consiste en una espectacularización el dolor como medio para su banalización: cuando la violencia deja de movilizar una respuesta crítica y pasa a normalizar el estado de excepción.

Sin embargo, la ilustración de los mecanismos de ofuscación es sólo crítica teórica de la substancia de las representaciones imaginarias, no la remoción de los deseos a los que aquellas representaciones presuponen satisfacer. Este último campo ya no pertenece a la crítica teórica sino a la política, y la crítica se acaba con mostrar los usos alternativos de los medios de producción existentes en cada momento. Este podría ser el resumen de "Filmtransparente" 34 , un análisis de las posibilidades ilustradoras de la producción cinematográfica dominada por modelo de representación que no consigue satisfacer las promesas dadas a sus consumidores y, por tanto, no sólo no cancelan sus contradicciones sino que más bien las agudizan y las muestran claramente. La movilización crítica de los afectos y la construcción de imaginarios alternativos serían, tal es la tesis de la "izquierda lacaniana" 35 , el necesario paso siguiente.

\section{Referencias bibliográficas}

Adorno, T.W. (2008), Crítica de la cultura y sociedad, trad. de J. Navarro. Madrid: Akal. Adorno, T.W. (2009), Escritos sociológicos II, vol. 1, trad. de A. González. Madrid: Akal Amengual, G. (2007), Antropología filosófica, Madrid: BAC.

Benjamin, W. (2008), "La obra de arte en la época de su reproductibilidad técnica”, en: Ibíd., Obras, vol. I-2, Madrid: Ábada.

Cabot, M. (2007), «Sobre los medios técnicos y la renovación de tradiciones. Walter Benjamin y el concepto de "experiencia", pensado desde la estética», en: Amengual, G., Cabot, M., Vermal, J.L., Ruptura de la tradición. Ensayos sobre Benjamin y Heidegger, Madrid: Trotta.

Descartes, R. (1977), Meditaciones metafísicas con objeciones y respuestas, trad. de V. Peña. Madrid: Alfaguara.

34 Adorno, T.W., "Filmtransparente", in: GS, 10.1, pp. 353-361.

35 Stavrakakis, Y., La izquierda lacaniana. Psicoanálisis, teoría, política, trad. L. Mosconi. Buenos Aires: F.C.E., 2010 . 
Descartes, R. (2005), Las pasiones del alma, trad. de T. Onaindia. Madrid: Edaf.

Duque, F. (1998), Historia de la filosofía moderna. La era de la crítica. Madrid: Akal.

Eisler, R. (1964), Kant-Lexikon. Nachschlagewerk zu Kants sämtlichen Schriften, Briefen und handschriftlichen Nachlaß. Hildesheim: Georg Olms Verlagsbuchhandlung.

Ford, H. (1923), My Life and Work, New York: Doubleday, Page \& Co.

Freud, S. (1991a), “Conferencias de introducción al psicoanálisis”, Obras Completas, vol. 15, Buenos Aires: Amorrortu.

Freud, S. (1991b), "El malestar en la cultura", in: Obras Completas, vol. 21, Buenos Aires: Amorrortu.

Hegel, G.W.F. (1955), Lecciones sobre la historia de la filosofía, trad. de W. Roces. México: FCE.

Hegel, G.W.F. (2005), Enciclopedia de las ciencias filosóficas en compendio. trad. de R. Valls. Madrid: Alianza Editorial.

Kojeve, A. (2013), Introducción a la lectura de Hegel, trad. de A. Alonso. Madrid: Trotta.

La Boétie, E. (2008), Discurso de la servidumbre voluntaria o el contra uno, trad. de P. Lamba. Madrid: Trotta.

Lacan, J. (2013), Escritos I, trad. T. Segovia. Madrid: Biblioteca Nueva.

Marx, K. (1978), Contribución a la crítica de la economía política, trad. de J. Merino. Madrid: Alberto Corazón.

Roudinesco, E. (2000), La batalla de los cien años: historia del psicoanálisis en Francia, trad. de I. Gárate. Madrid: Fundamentos.

Scheler, M. (1982), El puesto del hombre en el cosmos, trad. de J. Gaos. Buenos Aires: Losada.

Stavrakakis, Y. (2007), Lacan y lo político, trad. de L. Barbieri y M. Valente. Buenos Aires: Prometeo Libros.

Stavrakakis, Y. (2010), La izquierda lacaniana. Psicoanálisis, teoría, política, trad. L. Mosconi. Buenos Aires: F.C.E.

Zamora, J.A. (2007), "El enigma de la docilidad", en: Cabot, M. (ed.), El pensamiento de Th. W. Adorno: balance y perspectivas. Palma de Mallorca: Edicions UIB, pp. 27-42. 
